\title{
SYNTHESIS OF NEW AMIDES BASED ON THE N-HYDROXYACETYLATION OF P- TOLUIDINE
}

\author{
E. N. KHURRAMOV' ${ }^{1}$, A. K. ABDUSHUKUROV ${ }^{2}$, D. M. BURIYEVA ${ }^{3}$, E. T. BERDIMURODOV ${ }^{4 *}$ \\ \& I. NAKHATOV \\ ${ }^{1,2,3}$ Faculty of Chemistry, National University of Uzbekistan, Tashkent, Uzbekistan \\ ${ }^{4,5}$ Faculty of Natural Sciences, Karshi State University, Karshi, Uzbekistan
}

\begin{abstract}
In this research work, new amides including p-toluidiniumglycolate and 2-hydroxy-N-(4-methyl)phenylacetamidewere synthesized based on the $N$-hydroxyacetylation of p-toluidine. Their structure was proven by IR and ${ }^{1} H$ NMR spectroscopic methods. The synthesis methodology of new amides based on the N-hydroxyacetylation of p-toluidine was created, revealing that p-toluidiniumglycolate was formed in the environment without a catalyst and 2-hydroxy-N-(4methyl)phenylacetamide was synthesized in the presence of an acetic acid catalyst in $85 \%$ and $94 \%$ reaction yields, respectively. These synthesized compounds'frequencies of the different bonds were theoretically computed and comprised with experimental results by DFT calculations with the B3LYP method $(6-311 G(d, p))$, revealing that the similarity degrees between quantum and experimental results reported at around 95-97\%. The energy differences between LUMO and HOMO for both studied organic molecules reported 0.2 and $0.148 \mathrm{eV}$ respectively, confirming that both molecules are lower stability and higher reactivity.

KEYWORDS: Amides, N-hydroxyacetylation, p-Toluidine, Organic Synthesis, DFT \& Acetic Acid
\end{abstract}

Received: May 13, 2020; Accepted: Jun 03, 2020; Published: Aug 03, 2020; Paper Id.: IJMPERDJUN2020570

\section{INTRODUCTION}

The carbonic acid amides and their derivatives are predominantly organic compounds, which are the main antidepressants in medicine. For example, paracetamol, phenacetin and filament, which are now widely used in modern medicine. The main active ingredient of these drugs is acrylamides of aliphatic carboxylic acids [1-3]. These drugs have been used for many years and have not lost their practical importance in modern medicine. At the same time, it was found that new organic compounds based on amides, which have been mostly synthesized in recent years, are active compounds that can be used in medicine to treat various diseases [4-6].

Acrylamides of aliphatic and aromatic carboxylic acidsare based on organic chemicals widely used in agriculture and veterinary.Aromatic carbonic acrylamides are the main components in organic chemistry, which wereutilized in agriculture, such as Zincundan, Alanap and Boscalid. These compoundshave high biological activity and alsoused in the chemical industry in recent years [5, 7-9]. The general chemical structures of these compounds contain the alkyl and acrylamides of aliphatic and aromatic carbonic acidsas follows:<smiles>[R]NC([R])=O</smiles> 
It should be noted that these compounds are still synthesized by the reaction of acid anhydrides or halogen anhydrides with amino compounds. These reactions are called $\mathrm{N}$-acetylation of amines and the most dominant one in organic chemistry. It was found that the aromatic amines react with carboxylic acids in the presence of appropriate catalysts, such as the various halogens of phosphorus, phosphoric acids, metal complexes and salts [10,11]. N-Acetylation of amines with carbonic acid is a complex process, which is explained by the fact that the activity of carboxylic acids is lower than that of acid anhydrides or halogen anhydrides. Therefore, the course of these reactions directly depends on some factors such as the catalyst, temperature, and nature of the solvent $[12,13]$.

In modern times, the anticorrosion properties of amines have been explored because they are effective adsorbents on the metal surface, for example, steel. The nitrogen atoms in amine compounds are more electron-rich, and these phenomena support these amines as more effective adsorbents. Thus, modern synthesized amines are widely used as a bestanticorrosion inhibitor in the gas and petrochemical industries [14-24].

In this research work, new amides were synthesized based on N-hydroxyacetylation on p-toluidine and created their syntheses methodology, and also their structures were proven by IR and ${ }^{1} \mathrm{H}$ NMR spectroscopic methods. The obtained experimental spectroscopic results were compared with the quantum DFT results.

\section{MATERIALS AND METHODS}

\subsection{Structural and Physical Analysis Methods}

In this investigation work, the structures of the new compounds were determined by IR spectra on a Systemoph-2000 IR spectrophotometer ( $\mathrm{K}$ Br press disc, $\left.400-4000 \mathrm{~cm}^{-1}\right)$ and ${ }^{1} \mathrm{H}$ NMR spectra on a UNITY $400+$ spectrometer $\left(\mathrm{CD}_{3}\right)_{2} \mathrm{SO}+\mathrm{CCl}_{4}$ solutions, $400 \mathrm{MHz}$ ). $\mathrm{R}_{\mathrm{f}}$ values of these compounds were found on LS 5/40 silica gel plates with benzene: acetone solvent systems. Developers: UV light, Dragendorf reagent. The melting temperatures of these compounds were derived on a "BOETIUS" equipment [2-10].

\subsection{Computational Methods}

The B3LYP method was utilized in the DFT calculations of synthesized organic moleculesdue to these chemicals are large molecules and require large integral equations. The 6-311G (d,p) basis sets were used in DFT calculations of the synthesized chemicals [25].

\section{RESULTS AND DISCUSSIONS}

\subsection{Syntheses Methodology}

It is known that the fourth ammonium salts are formedfrom the reaction between the R-carboxylic acids and R-amines in a good organic solvent by influence some catalyst. The reaction is the following:<smiles>[R]NC(=O)[OH+][R]N[18O]C([R])=O</smiles>

In the present study, the condensation reactions of glycolic acid with p-toluidine were investigated. The influence of time, temperature, solvent and catalyst on the course of reactions was studied. First, these reactions were carried out in organic solvents by heating in a test tube with a Dean-Stark device. These synthetic compounds are called N-hydroxyacetyl 
products. Under these conditions, acrylamides are formed according to the following reaction:

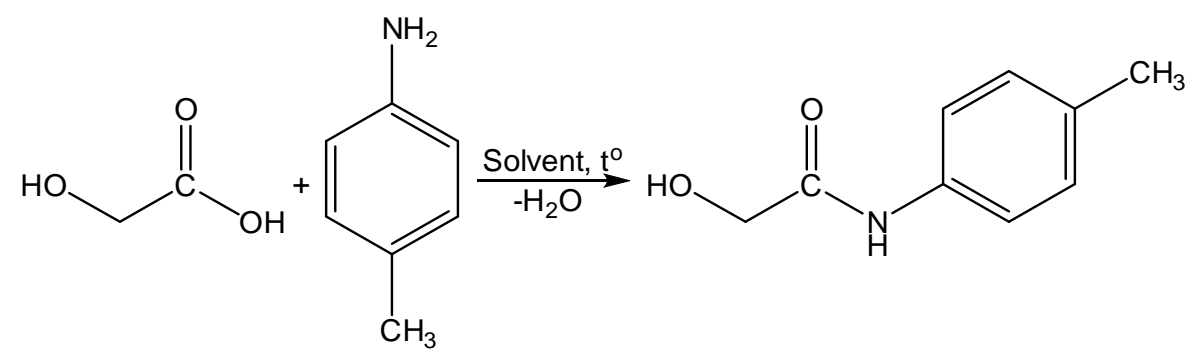

The reaction time of this acid-base condensation was monitored by determining the amount of water amount in Dean-Stark. The reaction yield of 2-hydroxy-N-(4-methyl) phenylacetamide increased with time and temperature growth, and the observed date revealed in table 1 . This reaction was undergone by a catalyst (acetic acid).

Table 1:The Reaction Methodology of Glycolic Acid with p-Toluidine in the Presence of Acetic Acid

\begin{tabular}{|c|c|c|c|c|}
\hline Product & Solvent & $\mathrm{T},{ }^{0} \mathrm{C}$ & Time, Hour & Yield, \% \\
\hline \multirow{8}{*}{ 2-Hydroxy-N- (4-methyl) phenylacetamide } & \multirow{4}{*}{ Benzene } & \multirow{4}{*}{80} & 1 & 32 \\
\hline & & & 2 & 53 \\
\hline & & & 3 & 76 \\
\hline & & & 4 & 81 \\
\hline & \multirow{4}{*}{ Toluene } & \multirow{4}{*}{110} & 1 & 42 \\
\hline & & & 2 & 69 \\
\hline & & & 3 & 90 \\
\hline & & & 4 & 94 \\
\hline
\end{tabular}

From the results in table 1, it was reported that the reaction yield of the product increased as the reaction temperature rise in the presence of a catalyst (acetic acid).

p-Toluidiniuśmglycolate was formed when this reaction was undergone without the catalyst. The difference between the reaction with and without a catalyst is that the condensation of glycolic acid with amines depends on the solubility of the product, and the solubility of acetic acid promotes the separation of water (Scheme 1).

The acetic acid in the condensation reaction of glycolic acid with aromatic amines increases the stability of the more density ion pair, which is formed by the reaction of acids and amino acids in the intermediate phase of the reaction. The following scheme was proposed to describe the process:<smiles>[R]NC(=O)CO</smiles> 
Scheme 1.N-Hydroxyacetylationof amines by catalysis - acetic acid-forming hydrogen bonds

It should be noted that in these reactions, acetic acid simultaneously acts as a catalyst and solvent. At the same time, the positive charge of the carbonyl carbon atom in glycolic acid is more electron density than that of acetic acid $\left(\delta^{+}\right)$. The nitrogen atom of the amino compounds initially attacks glycolic acid and forms an intermediate molecule. The hydrogen bonds of the hydrocarbon group and hydroxyl hydrogen in the carboxyl group, and the amino compounds hydrogen with the carbonyl group and oxygen improve the stability of the intermediate molecule. As a result, the release of water in acid-base condensation reactions is easy going.

A catalyst scheme has been proposed to show the effects of acetic acid in the reaction. The reaction mechanism corresponds to the classical mechanism of nucleophilic substitution of $\mathrm{S}_{\mathrm{N}} 2$ in the carbonyl carbon of an acid (Scheme 2).

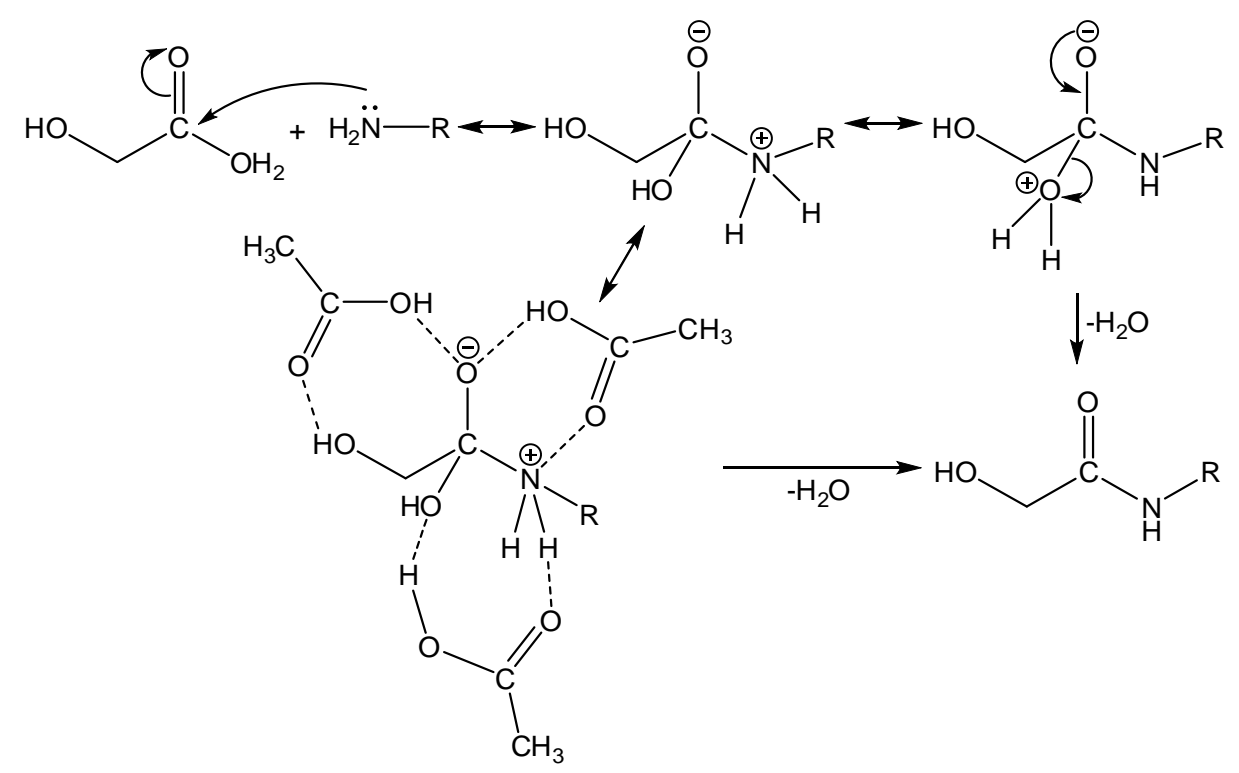

Scheme 2. Mechanism of N-hydroxyacetylation reactions of amines by acetic acid catalyst.

According to the proposed Scheme 2, it can be assumed that acetic acid can also neutralize intermediate $\mathrm{N}^{+}$and $\mathrm{O}^{2-}$ ions by the action of amino acids on carbonyl carbon. The solubility of carboxylic acids and amines in the solvent and the formation of hydrogen bonds are more stable.

All synthesized amide compounds were isolated and the irpurity degree of them has confirmed by LS 5/40 silica gel plates with benzene: acetone solvent systems. The structure of the product molecules was studied and confirmed using IR and ${ }^{1} \mathrm{H}$ NMR spectroscopy (the results of the analysis are presented in the experimental section).

\subsection{Spectroscopic Analysis}

It has already been mentioned in the literature above that the reaction between the carboxylic acids and amines leads to the formation of quaternary ammonium salts. Accordingly, in this study, intermediate products such as quaternary ammonium salts were isolated. The IR spectra of the starting materials, intermediates and the final reaction product were compared and the spectral results were analyzed. A comparison of the IR spectra of 2-hydroxy-N- (4-methyl) phenylacetamide, an intermediate formed by glycolic acid, p-toluidine and their reaction, is given below. 


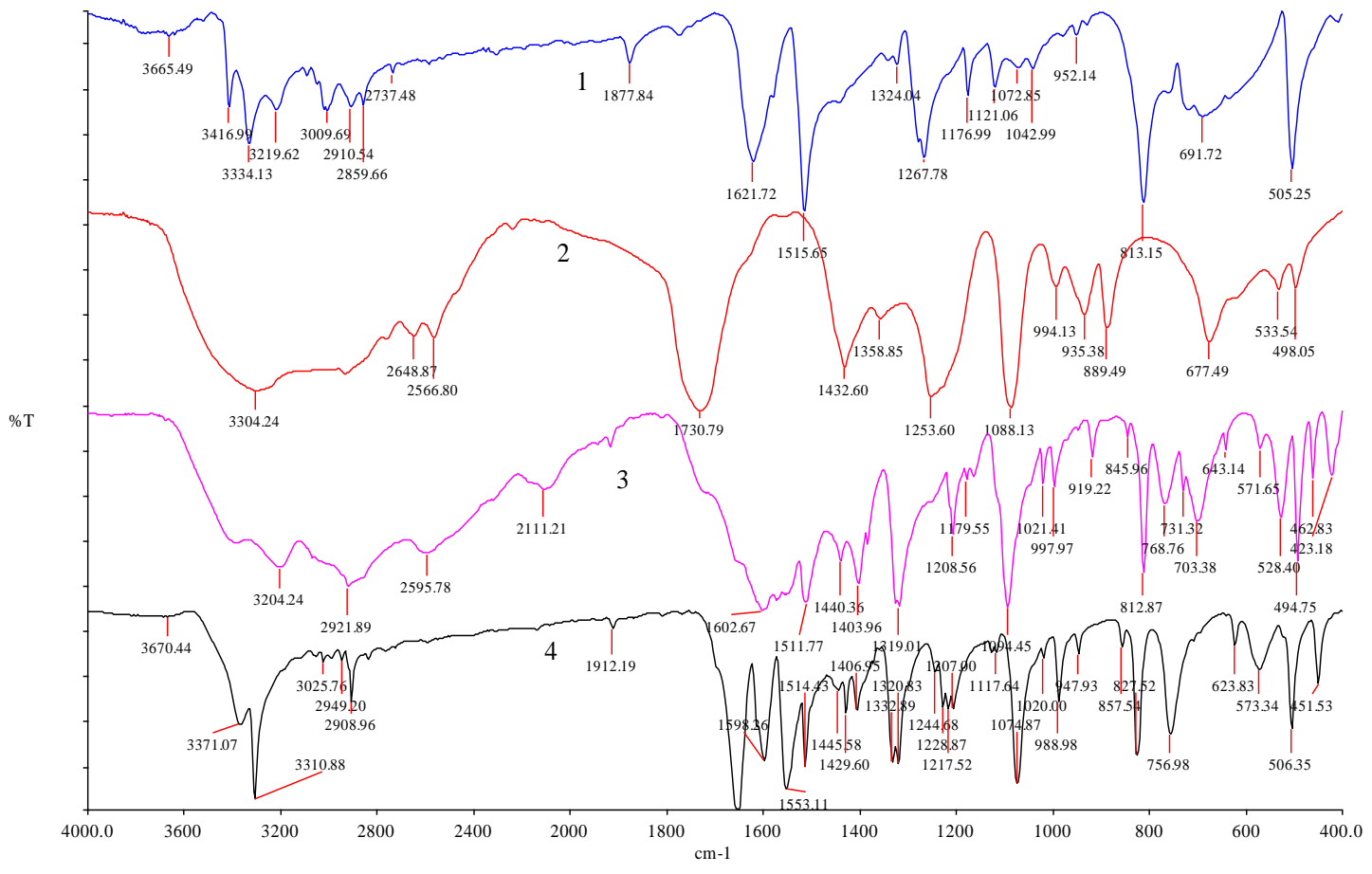

Figure 1.Experimental IR Spectra of Starting Materials and Reaction Products: 1 is p-Toluidine, 2 is Glycolic Acid, 3 is p-Toluidiniumglycolate, and 4is 2-Hydroxy-N-(4-Methyl) Phenylacetamide.

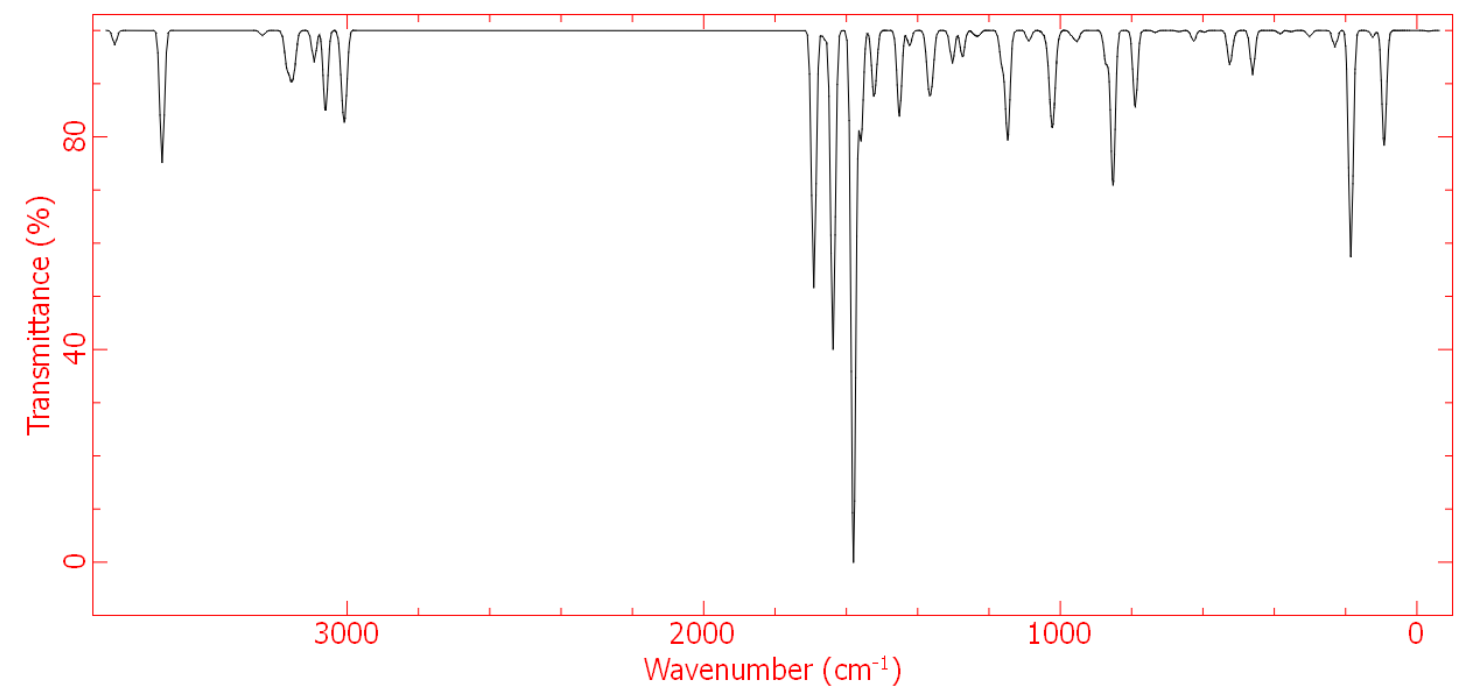

Figure 2: Theoretical IR Spectra of 2-Hydroxy-N-(4-Methyl) Phenylacetamide and p-Toluidiniumglycolate. 


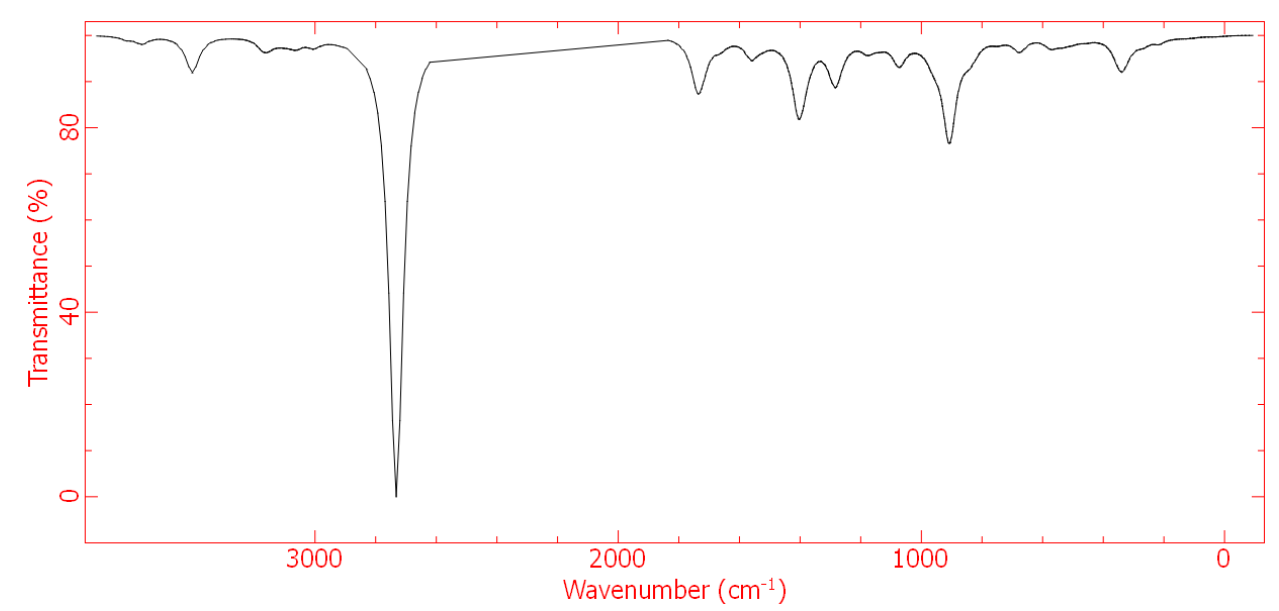

Figure 3: Theoretical IR Spectra of p-Toluidiniumglycolate.

The results of the spectrum show (figure1) that the IR spectrum of p-toluidine contains (1) $3334.13 \mathrm{~cm}^{-1}$ is the freevalence vibrations of the $-\mathrm{NH}_{2}$ group and the IR spectrum of the intermediate salt (3) is a valence with a high valency of the protonated nitrogen atom vibrations can be seen. This also confirms that the loss of oscillations of deformation for the carbonyl group in salt (3) and glycolic acid (2) appeared at $1730.79 \mathrm{~cm}^{-1}$. Intensive absorption of the NH group in the amide bond in 4-hydroxy-N-(4-methyl)phenylacetamide (4) revealed at $3310.88 \mathrm{~cm}^{-1}$ and deformation vibrations of the $\mathrm{C}=\mathrm{O}$ group in the amide bond represented at $1652.08 \mathrm{~cm}^{-1}$ (Table 2). The formation of salt indicates that the salt is dehydrated and converted to an amide.

Table 2: Theoretical and Experimental IR Frequencies $\left(\mathrm{cm}^{-1}\right)$ of 2-Hydroxy-N-(4-Methyl)

Phenylacetamide and p-Toluidiniumglycolate

\begin{tabular}{|c|c|c|c|}
\hline Molecular Structure & Frequencies of Different Bond & Experimental & DFT \\
\hline \multicolumn{4}{|c|}{ 2-Hydroxy-N-(4-Methyl)Phe\&nylacetamide } \\
\hline \multirow{11}{*}{$\mathrm{HO}_{\mathrm{H}^{-}}$} & $v_{\mathrm{s}}(\mathrm{C}=\mathrm{O})$ & 1652 & 1653.93 \\
\hline & $v_{\mathrm{s}}(\mathrm{NH})$ & 3310 & 3270.20 \\
\hline & $v_{\mathrm{s}}(\mathrm{OH})$ & 3371 & 3554.34 \\
\hline & $v_{\mathrm{as}}\left(\mathrm{CH}_{3}\right)$ & 2949 & 1708.35 \\
\hline & $v_{\mathrm{as}}\left(\mathrm{CH}_{2}\right)$ & 2908 & 1708.35 \\
\hline & $\mathrm{C}-\mathrm{O}$ & 1074 & 1099.44 \\
\hline & $\delta(\mathrm{NH})$ & 1553 & 1595.95 \\
\hline & $\delta(\mathrm{OH})$ & 1445 & 1465.96 \\
\hline & $\delta\left(\mathrm{CH}_{3}\right)$ & 1514 & 1532.09 \\
\hline & $\delta\left(\mathrm{CH}_{2}\right)$ & 1332 & 1315.92 \\
\hline & $\delta \mathrm{C}-\mathrm{N}$ & 1598 & 1595.95 \\
\hline \multicolumn{4}{|l|}{ p-Toluidiniumglycolate } \\
\hline \multirow{11}{*}{$\mathrm{C}_{\odot}^{\mathrm{O}}$} & $v_{\text {as }}\left(\mathrm{COO}^{\square}\right)$ & 1602 & 1575.97 \\
\hline & $v_{\mathrm{s}}\left(\mathrm{COO}^{\square}\right)$ & 1403 & 1418.27 \\
\hline & $v_{\mathrm{S}}\left(\mathrm{N}^{+}-\mathrm{H}\right)$ & 2921-3204 & 2759.66-3208.37 \\
\hline & $v_{\mathrm{s}}(\mathrm{OH})$ & 3383 & 3438.93 \\
\hline & $\mathrm{C}-\mathrm{O}$ & 1094 & 1083.38 \\
\hline & $\delta\left(\mathrm{COO}^{\square}\right)$ & 703 & 683.16 \\
\hline & $\delta\left(\mathrm{N}^{+}-\mathrm{H}\right)$ & $1555-1650$ & $1575.97-1680.43$ \\
\hline & $\delta(\mathrm{OH})$ & 1440 & 1418.27 \\
\hline & $\delta\left(\mathrm{CH}_{3}\right)$ & 1511 & 1522.66 \\
\hline & $\delta\left(\mathrm{CH}_{2}\right)$ & 1319 & 1306.70 \\
\hline & $\delta \mathrm{C}-\mathrm{N}$ & 1572 & 1575.97 \\
\hline
\end{tabular}


Table 3: Experimental ${ }^{1} \mathrm{H}$ NMR (ppm) Values for the2-Hydroxy-N-(4-Methyl) Phenylacetamide and p-Toluidiniumglycolate

\begin{tabular}{|c|c|c|}
\hline Molecular Structure & ${ }^{1} \mathbf{H}$ positions & Experimental \\
\hline \multicolumn{3}{|c|}{ 2-Hydroxy-N-(4-Methyl)Phenylacetamide } \\
\hline \multirow{6}{*}{$\mathrm{HO}_{\mathrm{H}^{\prime}}$} & $\mathrm{H},(\mathrm{OH})$ & $9.119, \mathrm{~s}$ \\
\hline & $2 \mathrm{H}(\mathrm{ArH}-2,6)$ & $7.471 \mathrm{~d}(J=8.3, \mathrm{H}-2.05)$ \\
\hline & $2 \mathrm{H}(\mathrm{ArH}-3,5)$ & $6.987 \mathrm{~d}(J=8.3, \mathrm{H}-2.06)$ \\
\hline & $\mathrm{H}(\mathrm{NH})$ & $5.393, \mathrm{~s}$ \\
\hline & $2 \mathrm{H}\left(\mathrm{CH}_{2}\right)$ & $3.878, \mathrm{~s}$ \\
\hline & $3 \mathrm{H}\left(\mathrm{Ar}-\mathrm{CH}_{3}\right)$ & $2.238, \mathrm{~s}$ \\
\hline \multicolumn{3}{|c|}{ p-Toluidiniumglycolate } \\
\hline \multirow{6}{*}{$\mathrm{CO}_{\mathrm{O}}^{\mathrm{HO}}$} & $\mathrm{H}(\mathrm{OH})$ & $9.21, \mathrm{~s}$ \\
\hline & $2 \mathrm{H}(\mathrm{ArH}-2,6)$ & $6.747, \mathrm{~d}(J=8.26, \mathrm{H}-1.96)$ \\
\hline & $2 \mathrm{H}(\mathrm{ArH}-3,5)$ & $6.38, \mathrm{~d}(J=8.3, \mathrm{H}-1.95)$ \\
\hline & $3 \mathrm{H}\left({ }^{+} \mathrm{NH}_{3}\right)$ & $4.16, \mathrm{~s}$ \\
\hline & $2 \mathrm{H}\left(\mathrm{CH}_{2}\right)$ & $3.55, \mathrm{~s}$ \\
\hline & $3 \mathrm{H}\left(\mathrm{Ar}-\mathrm{CH}_{3}\right)$ & $2.13, \mathrm{~s}$ \\
\hline
\end{tabular}

\subsection{DFT-Spectrical Comparison}

In this study work, the first synthesized 2-hydroxy-n-(4-methyl) phenylacetamide and p-to luidiniumglyco late frequencies of different bonds were theoretically computed and comprised of experimental results. We have used DFT calculations with the B3LYP method (6-311G (d, p)) (figure 2 and 3). At the start of IR computation, 2-hydroxy-n-(4-methyl) phenylacetamide and p-to luidiniumgly colate were optimized. In the DFT calculations, the IR frequencies were scaled to 0.9587. 2-Hydroxy$\mathrm{n}$-(4-methyl) phenylacetamide and p-to luidiniumgly collate were optimized with tetramethylsilane in NMR calculations (figure 6 and figure 7).

The experimental frequencies of 2-hydroxy-n-(4-methyl) phenylacetamide and p-toluidiniumglycolate(figure 4 and 5) were compared to the theoretical frequencies of these molecules (figure 6 and 7). The DFT and experimental frequencies of the bonds are listed in table 3. It is clear from this observed date that the experimental and computed frequencies were different at low percentages because of the following reasons; DFT can calculate frequencies in the gaseous phase; experimental results were obtained in the solid phase and could not calculate harmonic frequencies. DFT can calculate harmonic frequencies, but these harmonic frequencies were levelled down using a 0.9587 scaling factor to contrast the experimental results. 


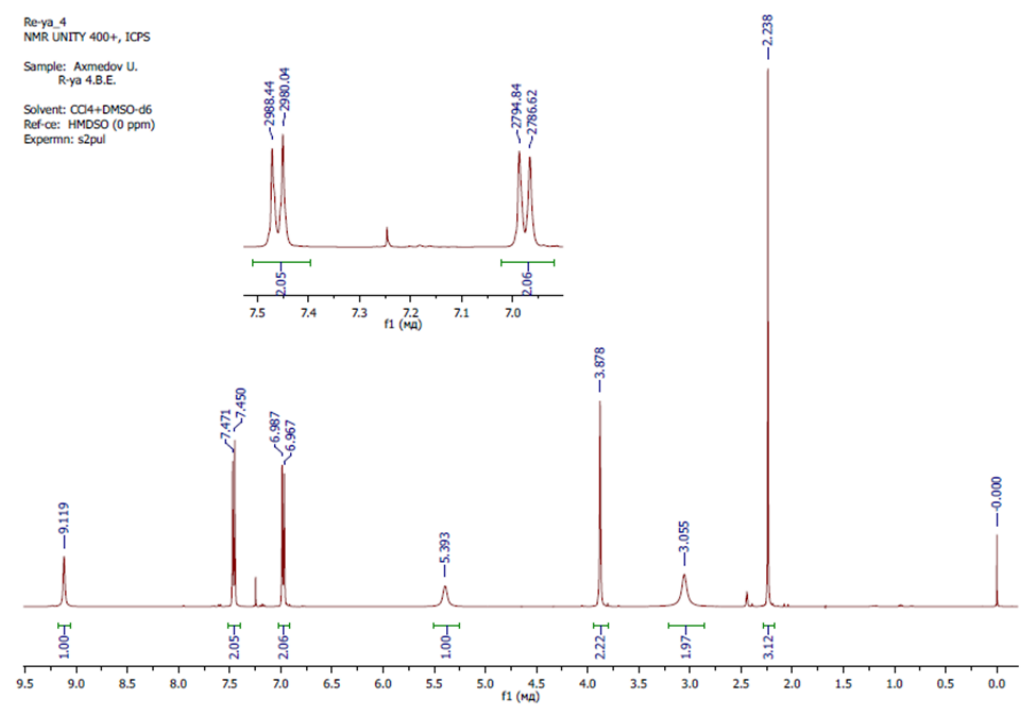

Figure 4: Experimental ${ }^{1} \mathrm{H}$ NMR Spectra of 2-Hydroxy-N-(4-Methyl)Phenylacetamide.
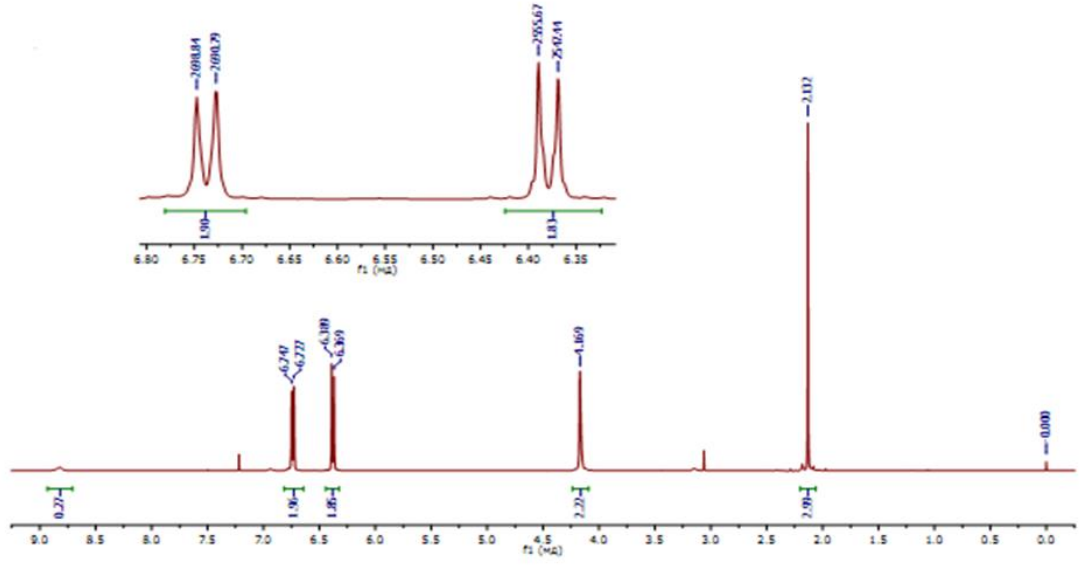

Figure 5: Experimental ${ }^{1} \mathrm{H}$ NMR Spectra of p-Toluidiniumglycolate. 


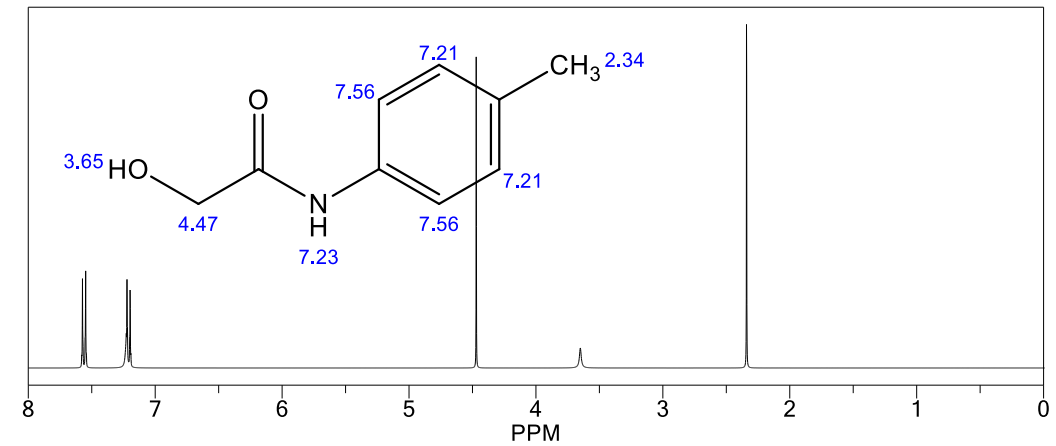

Protocol of the H-1 NMR Prediction:

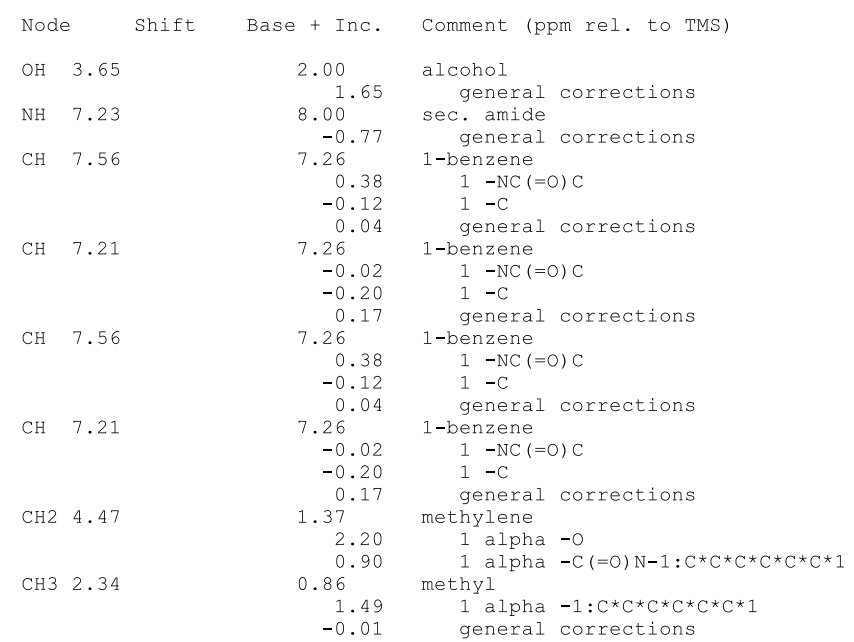

1H NMR Coupling Constant Prediction

shift atom index coupling partner, constant and vector

\begin{tabular}{rrrrl}
3.65 & 1 & & & \\
7.23 & 5 & & & \\
7.56 & 7 & & & \\
& & 8 & 7.5 & $\mathrm{H}-\mathrm{C}^{\star} \mathrm{C}-\mathrm{H}$ \\
7.21 & 8 & 11 & 1.5 & $\mathrm{H}-\mathrm{C}^{*} \mathrm{C}^{\star} \mathrm{C}-\mathrm{H}$ \\
& & 7 & 7.5 & $\mathrm{H}-\mathrm{C}^{*} \mathrm{C}-\mathrm{H}$ \\
7.56 & 11 & 10 & 1.5 & $\mathrm{H}-\mathrm{C}^{\star} \mathrm{C}^{\star} \mathrm{C}-\mathrm{H}$ \\
& & 10 & 7.5 & $\mathrm{H}-\mathrm{C}^{\star} \mathrm{C}-\mathrm{H}$ \\
7.21 & 10 & 7 & 1.5 & $\mathrm{H}-\mathrm{C}^{*} \mathrm{C}^{\star} \mathrm{C}-\mathrm{H}$ \\
& & 11 & 7.5 & $\mathrm{H}-\mathrm{C}^{*} \mathrm{C}-\mathrm{H}$ \\
4.47 & 2 & 8 & 1.5 & $\mathrm{H}-\mathrm{C}^{*} \mathrm{C}^{\star} \mathrm{C}-\mathrm{H}$ \\
2.34 & 12 & & & \\
\hline
\end{tabular}

Figure 6: Theoretical ${ }^{1}$ H NMR (ppm) Values for 2-Hydroxy-N-(4-Methyl) Phenylacetamide. 

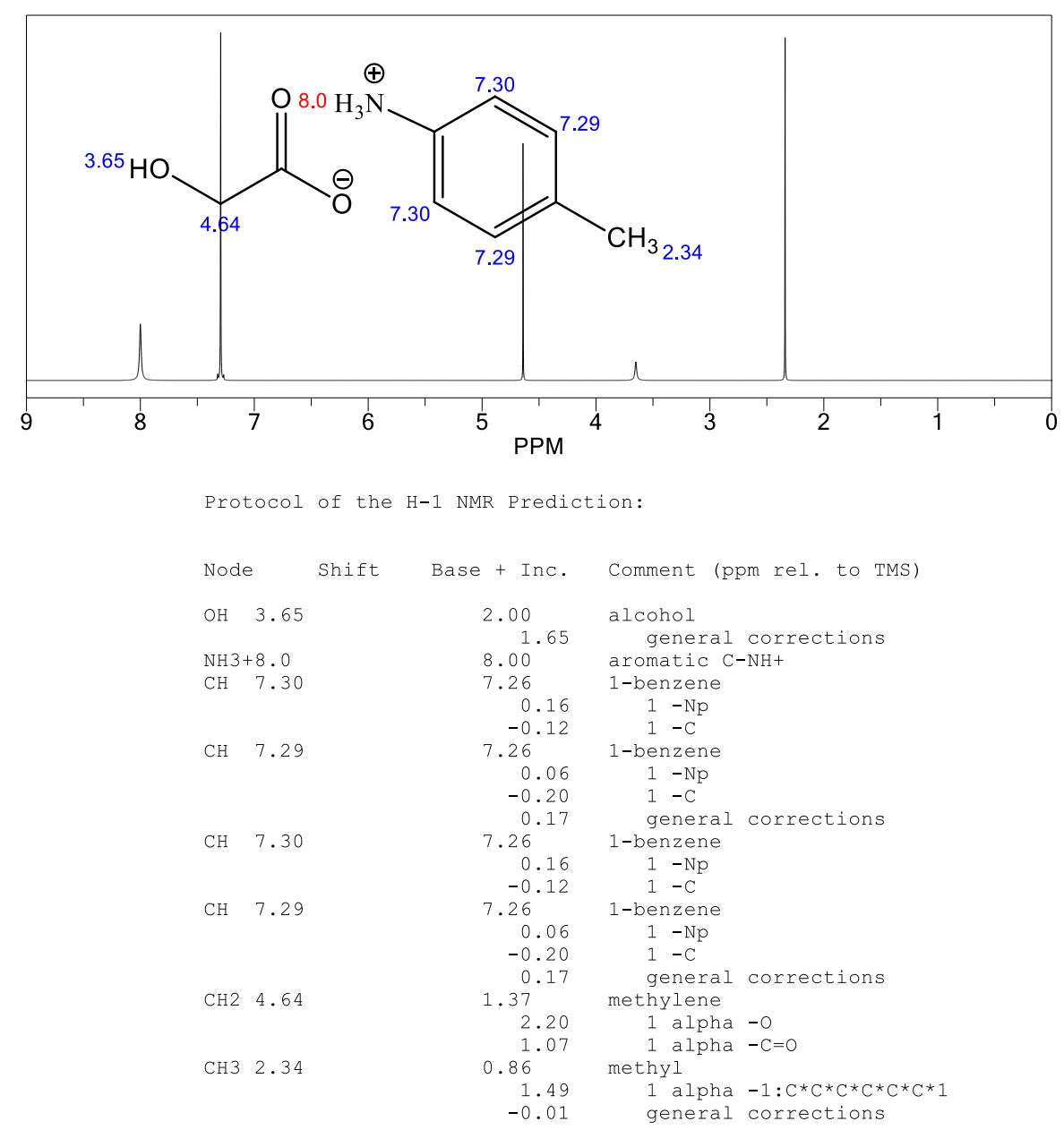

$1 \mathrm{H}$ NMR Coupling Constant Prediction

shift atom index coupling partner, constant and vector

$\begin{array}{ll}3.65 & 1 \\ 8.0 & 6 \\ 7.30 & 8\end{array}$

$9 \quad 7.5 \quad \mathrm{H}-\mathrm{C}{ }^{\star} \mathrm{C}-\mathrm{H}$

$7.29 \quad \begin{array}{llll}12 & 1.5 & \mathrm{H}-\mathrm{C}^{*} \mathrm{C}{ }^{*} \mathrm{C}-\mathrm{H}\end{array}$

$\begin{array}{rrrl}8 & 7.5 & \mathrm{H}-\mathrm{C} * \mathrm{C}-\mathrm{H} \\ 11 & 1.5 & \mathrm{H}-\mathrm{C}{ }^{\star} \mathrm{C}{ }^{\star} \mathrm{C}-\mathrm{H}\end{array}$

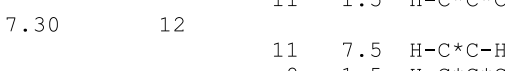

$7.29 \quad 11 \quad 8 \quad 1.5 \quad \mathrm{H}-\mathrm{C} * \mathrm{C} * \mathrm{C}-$

$\begin{array}{rrl}12 & 7.5 & \mathrm{H}-\mathrm{C}{ }^{*} \mathrm{C}-\mathrm{H} \\ 9 & 1.5 & \mathrm{H}-\mathrm{C}{ }^{*} \mathrm{C} * \mathrm{C}-\mathrm{H}\end{array}$

$\begin{array}{lr}4.64 & 2 \\ 2.34 & 13\end{array}$

Figure 7: Theoretical ${ }^{1} \mathrm{H}$ NMR (ppm) Values for p-Toluidiniumglycolate.

\subsection{Frontier Molecular Orbital Test}

The frontier molecular orbital computations are used to determine the molecular descriptors of investigated organic molecules. In this article, the molecular descriptors of 2-hydroxy-N-(4-methyl) phenylacetamide and p-toluidiniumgly colate were computed through DFT-frontier molecular orbital quantum analysis. The molecular descriptors can show that the global reactivity and chemical structure characteristics of organic molecules. In this computed research, the molecular descriptors were derived according to Equations 1-7 and resulted in table 4 and 5.

Electronic chemical potential, $\mu(\mathrm{eV})=\mathrm{E}_{\mathrm{LUMO}}+\mathrm{E}_{\text {номо }} / 2$ 
Electronegativity, $\chi(\mathrm{eV})=-\left(\mathrm{E}_{\mathrm{LUMO}}-\mathrm{E}_{\mathrm{HOMO}}\right) / 2$

Global electrophilicity Index, $\omega(\mathrm{eV})=\mu^{2} / 2 \eta$

Chemical Softness, s $(\mathrm{eV})=1 / 2 \eta$

Chemical Hardness, $\eta(\mathrm{eV})=\mathrm{E}_{\mathrm{LUMO}}-\mathrm{E}_{\mathrm{HOMO}} / 2$

Ionization potential, $I(\mathrm{eV})=-E_{\text {Номо }}$

Electronic affinity, $A(\mathrm{eV})=-E_{L U M O}$

It is clear from computed results that 2-hydroxy-N-(4-methyl) phenylacetamide and p-toluidiniumgly collate are lower electronic affinity molecule. The reasons is that both molecule have more electron-donor atoms such as nitrogen and oxygen, which are responsible for being more reactive molecule. Next, obviously factor from results is that the ionization potential for 2-hydroxy-N-(4-methyl) phenylacetamide and p-to luidiniumgly colate accounted for 0.21 and $0.218 \mathrm{eV}$, confirming that both molecule are more ionized. It was known that the energy distinction ( $\left.\mathrm{E}_{\text {distinction}}\right)$ among the Lowest Unoccupied Molecular Orbitals and Highest Occupied Molecular Orbitals indicates the molecular stability. The E $\mathrm{distinction}_{\text {for }}$ 2-hydroxy-N-(4-methyl) phenylacetamide and p-to luidiniumgly collate reported 0.2 and 0.148 eV respectively, recommended that both molecules are lower stability and more reactivity. It is underlined in table 4 and 5 that both synthesized molecules are more chemical softness and lower hardness molecule.

The optimisation and charge distribution of studied organic molecules are represented in figure 8 and 11 . It is noticed that nitrogen and oxygen atoms are more negative atoms, which make a molecule more electro-donor. figure 9,12 for HOMO and figure 10, 13 for LUMO shows the active regions in molecular structure. HOMO is mainly distributed around nitrogen and oxygen atoms, these active sites are responsible for nucleophilicity attack. LUMO cited around carbon atoms, this LUMO cites attributed to electrophilic attacks.

Table 4: The Energy Values of Global Reactivity and Thermodynamic Parameters for 2-Hydroxy-N-(4-Methyl) Phenylacetamide. (298.150 K).

\begin{tabular}{|c|c|}
\hline Parameters, $\mathbf{e V}$ & $\begin{array}{c}\text { 2-Hydroxy-N-(4-Methyl) } \\
\text { Phenylacetamide. }\end{array}$ \\
\hline $\mathrm{E}_{\mathrm{LUMO}}$ & -0.01 \\
\hline $\mathrm{E}_{\mathrm{HOMO}}$ & -0.21 \\
\hline $\mathrm{E}_{\text {distinction }}$ & 0.2 \\
\hline $\mathrm{A}$ & 0.21 \\
\hline $\mathrm{I}$ & 0.01 \\
\hline$\eta$ & 0.1 \\
\hline$\chi$ & -0.1 \\
\hline$\mu$, & -0.11 \\
\hline$\omega$ & 0.06 \\
\hline $\mathrm{S}$ & 5 \\
\hline
\end{tabular}




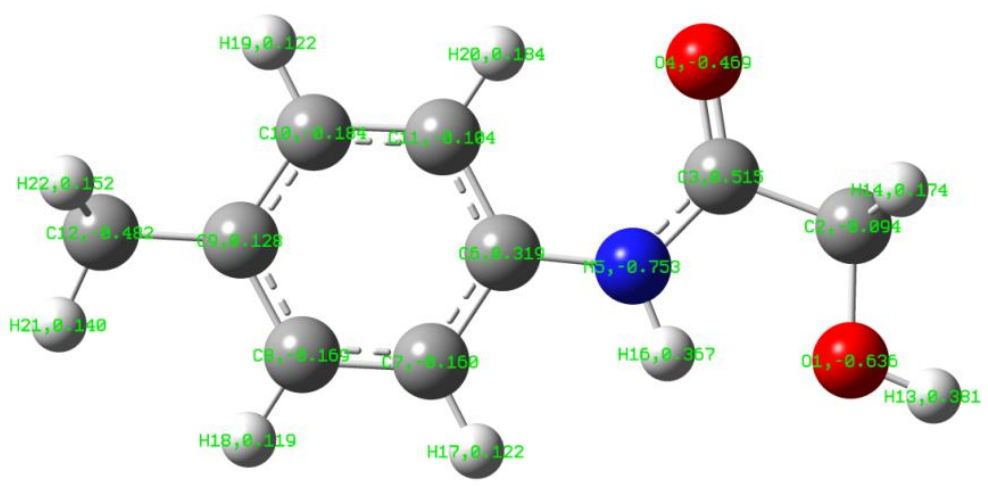

Figure 8: Optimisation and Charge Distribution of 2-HydroxyN-(4-Methyl) Phenylacetamide.

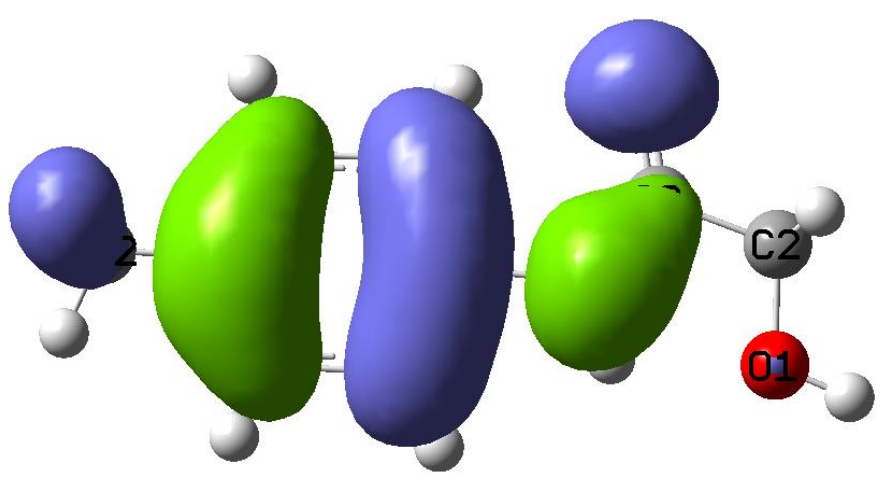

Figure 9: HOMO Orbitals of 2-Hydroxy-N-(4-Methyl) Phenylacetamide.

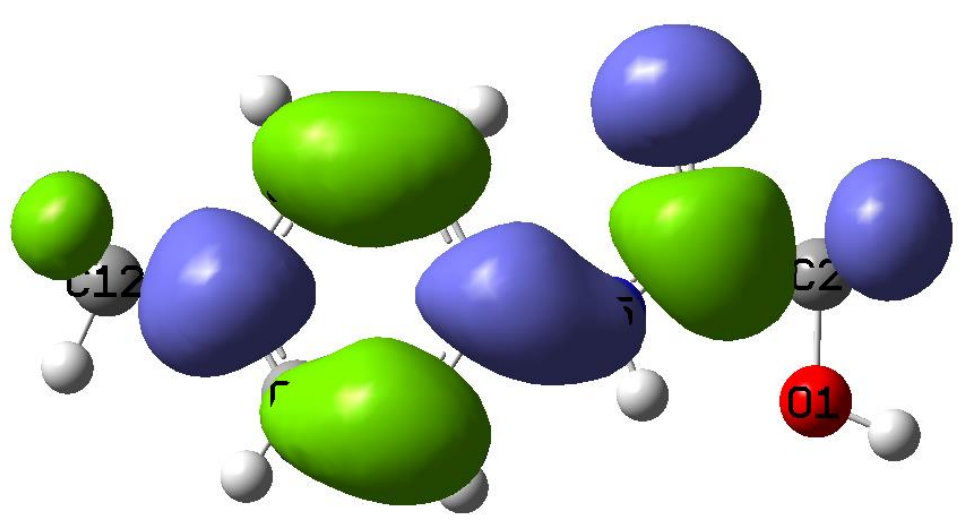

Figure 10: LUMO Orbitals of 2-Hydroxy-N-(4-Methyl) Phenylacetamide. 
Table 5: The Energy Values of Global Reactivity and Thermodynamic Parameters for p-Toluidiniumglycolate $(298.150 \mathrm{~K})$

\begin{tabular}{|c|c|}
\hline Parameters & p-toluidiniumglycolate \\
\hline $\mathrm{E}_{\mathrm{LUMO}}, \mathrm{eV}$ & -0.007 \\
\hline $\mathrm{E}_{\mathrm{HOMO}}, \mathrm{eV}$ & -0.218 \\
\hline $\mathrm{E}_{\text {distinction }}$ & 0.148 \\
\hline $\mathrm{A}$ & 0.218 \\
\hline $\mathrm{I}$ & 0.07 \\
\hline$\eta$ & 0.074 \\
\hline$\chi$ & -0.074 \\
\hline$\mu$, & -0.112 \\
\hline$\omega$ & 0.085 \\
\hline $\mathrm{s}$ & 6.76 \\
\hline
\end{tabular}

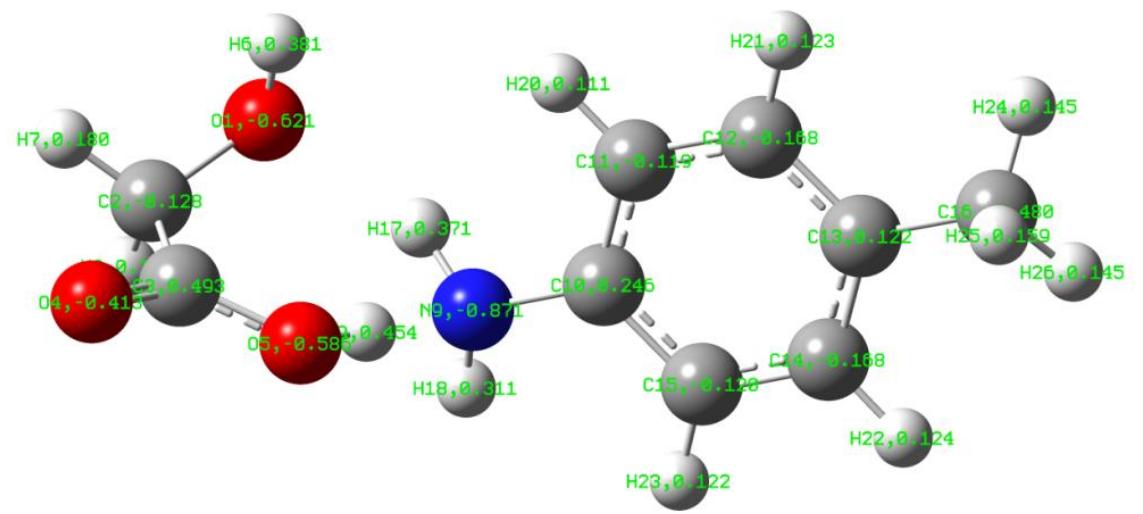

Figure 11: Optimisation and Charge Distribution of p-Toluidiniumglycolate.

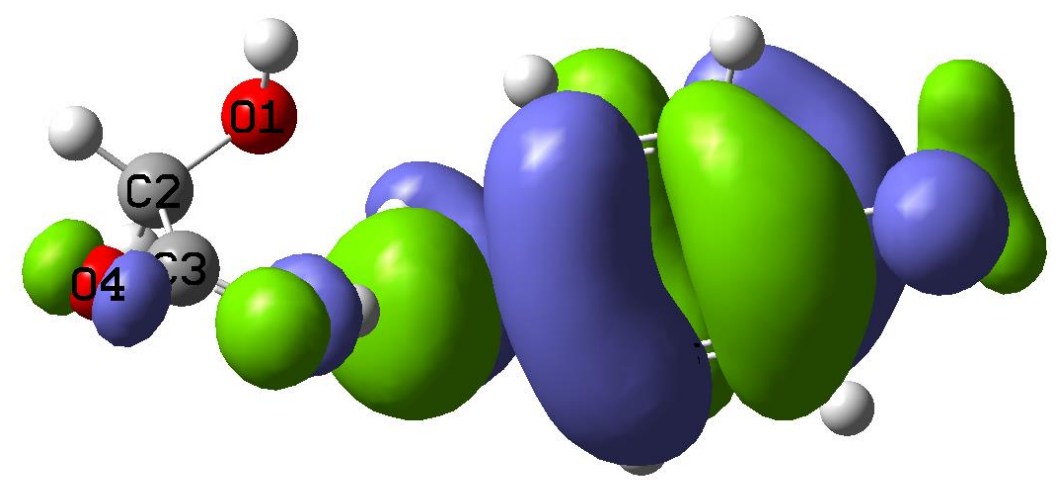

Figure 12: HOMO Orbitals of p-Toluidiniumglycolate. 


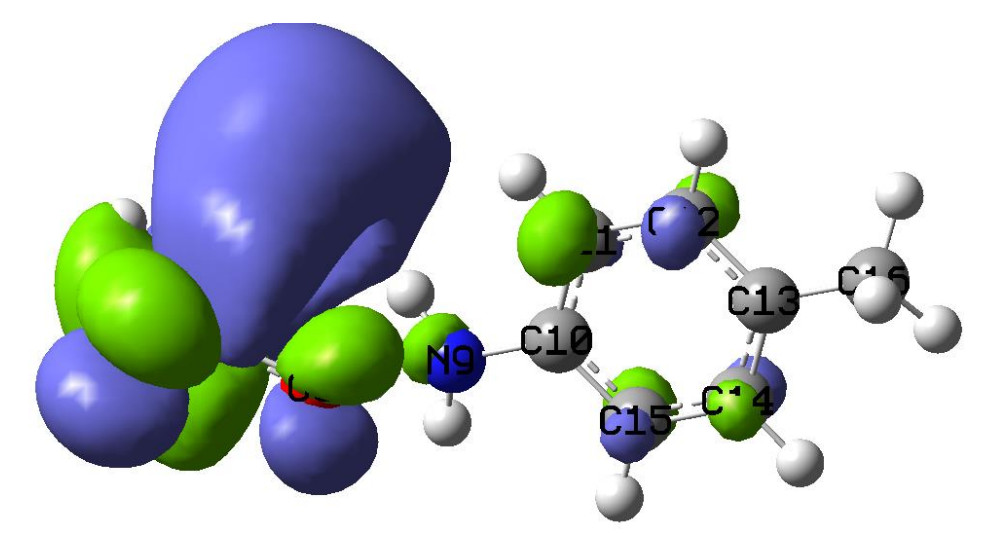

Figure 13: LUMO Orbitals of p-Toluidiniumglycolate.

\section{EXPERIMENTAL SECTION}

2-Hydroxy-N-phenylacetamide. (B) $0.836 \mathrm{~g}(0.011 \mathrm{~mol})$ of glycolic acid, $0.93 \mathrm{~g}(0.01 \mathrm{~mol})$ of aniline, $3 \mathrm{~g}$ of acetic acid, $20 \mathrm{ml}$ of toluene were mixed to a test tube with a water collector, and heated for 3 hours. Next, the reaction mixture was cooled and toluene was evaporated. Lastly, the obtained dry powder was neutralized in a soda solution (10\%), filtered and crystallized in a $40 \%$ ethanol-aqueous mixture. The weight of the product was 1,284 $\mathrm{g}(85 \%)$.

2-Hydroxy-N-(4-metyl) phenylacetamide. It is synthesized from glycolic acid and m-toluidine according tothe method (B). Reaction yield $90 \%$. The melting point was $139^{\circ} \mathrm{C} . \mathrm{R}_{\mathrm{f}}=0,26$ (benzene: acetone $=3: 1$, UV camera). IR spectra $\left(\mathrm{cm}^{-1}\right): 3371(\mathrm{OH}), 3310(\mathrm{NH}), 1652(\mathrm{C}=\mathrm{O}) .{ }^{1} \mathrm{H}$ NMR spectra(400 MHz, CCl + DMSO -d 6 , $\left.\delta, \mathrm{m} . \mathrm{s} ., \mathrm{J} / \mathrm{Hz}\right): 9.119(1 \mathrm{H}, \mathrm{s}$, $\mathrm{OH}), 7.471(2 \mathrm{H}, \mathrm{d}, J=8.3, \mathrm{H}-2,05), 6.987(2 \mathrm{H}, \mathrm{d}, J=8.3, \mathrm{H}-2.06), 5.393(1 \mathrm{H}, \mathrm{s}, \mathrm{NH}), 3.878\left(2 \mathrm{H}, \mathrm{s}, \mathrm{CH}_{2}\right), 2.23(3 \mathrm{H}, \mathrm{s}, \mathrm{Ar}-$ $\left.\mathrm{CH}_{3}\right)$.

p-Toluidiniumglycolate. A glass was filled with $0.57 \mathrm{~g}(0.0075 \mathrm{~mol})$ of glycolic acid in $7 \mathrm{ml}$ of ethanol, $0.8 \mathrm{~g}$ $(0.0075 \mathrm{~mol})$ of p-toluidine in ethanol and stored at room temperature. After ethanol was evaporated, the salt crystals remaining in the glass were separated, washed and dried. The weight of the product was 1,288 $\mathrm{g}(94 \%)$. The melting temperature of product represented $87^{\circ} \mathrm{C}$. IR spectra $\left(\mathrm{cm}^{-1}\right): 2921\left(\mathrm{NH}_{3}{ }^{+}\right), 1602\left(\mathrm{COO}^{-}\right), 3204(\mathrm{OH}) .{ }^{1} \mathrm{H}$ NMR spectra $(400$ MHz, $\mathrm{CCl}_{4}+\mathrm{DMSO}_{6}, \delta$, m.s., J/Hz): 9.21 (1 H, br. s, OH), 6.747 (2H, d, $\left.J=8.3, \mathrm{H}-1.96\right), 6.38$ (2H, d, J = 8.26, H-1.95), $4.16\left(3 \mathrm{H} \mathrm{s}, \mathrm{NH}_{3}{ }^{+}\right), 3.55\left(2 \mathrm{H}, \mathrm{s}, \mathrm{CH}_{2}\right), 2.14\left(3 \mathrm{H}, \mathrm{s}, \mathrm{CH}_{3}\right)$.

\section{CONCLUSIONS}

It was found that optimal properties and conditions of the reaction of N-hydroxyacetyltion of aniline with glycolic acid. In this method,it was easy to extract the product from the catalyst (acetic acid).

It is clear from the synthesized methodology that p-toluidinium glycolate was formed in the environment without a catalyst and 2-hydroxy-N-(4-methyl)phenylacetamide was firstsynthesized byan effective acetic acid catalyst in $85 \%$ and $94 \%$ reaction yields, respectively.

The obtained results indicated that the experimental and theoretical IR and NMR spectra of 2-hydroxy-n-(4-methyl) phenylacetamide and p-toluidinium glycolate were being 95-97\% similar.

The $\mathrm{E}_{\text {distinction }}$ for 2-hydroxy-N-(4-methyl) phenylacetamide and p-toluidinium glycolate reported 0.2 and $0.148 \mathrm{eV}$ respectively, recommended that both molecules are lower stability and more reactivity. 


\section{REFERENCES}

1. Mohamed ChafikBourkaib, Stephane Delaunay, Xavier Framboisier, Laurence Hôtel, Bertrand Aigle, Catherine Humeau, Yann Guiavarc'h, Isabelle Chevalo, $N$-acylation of L-amino acids in aqueous media: Evaluation of the catalytic performances of Streptomyces ambofaciensaminoacylases, Enzyme and Microbial Technology, Volume 137, June 2020, 109536.

2. JorisHulsbosch, Laurens Claes, Dirk E.DeVos, Zirconium-catalysed N-acylation of lactams using unactivated carboxylic acids, Tetrahedron Letters, Volume 59, Issue 17, 25 April 2018, Pages 1646-1650.

3. Koula, D. O. U. K. A. N. I., G. A. C. E. M. Nacera, and B. E. N. L. A. R. B. I. Hayat. "Physicochemical and phytochemical characterization of some Algerian honeys types." International Journal of Applied, Physical and Bio-Chemistry Research 4.6 (2014): 1-16.

4. Yuelian Xu, Simon E.Lopez, William R.DolbierJr., 1,1-Bis(dimethylamino)-2,2-difluoroethene, a diverse building block for the preparation of difluoroalkyl molecules. Acylation and condensation reactions, Journal of Fluorine Chemistry, Volume 229, January 2020, 109432.

5. Robert. S.L. Chapman, J.D. Tibbetts, S.D. Bull, 1,1-Diacyloxy-1-phenylmethanes as versatile N-acylating agents for amines, Tetrahedron, Vol. 74 (2018), pp. 5330-5339.

6. U.P. Saikia, F.L. Hussain, M. Suri, P. Pahari, Selective N-acetylation of aromatic amines using acetonitrile as acylating agent, Tetrahedron Letters, Vol. 57 (2016), pp. 1158-1160.

7. Pamila, Arul, S. Karpagam, and P. Jayaraman. "Morphological and Anatomical Features of Alternanthera Bettzickiana (regel) g. Nicholson. "International Journal of Botany and Research (IJBR) 8. 6, Dec 2018, 5-18

8. H. Asahara, T. Kida, T. Iwamoto, T. Hinoue, M. Akashi, Kinetic resolution of primary amines via enantioselective N-acylation with acyl chlorides in the presence of supramolecular cyclodextrinnanocapsules, Tetrahedron, Vol. 70 (2014), pp. 197-203.

9. Xiu-Zhi Wang, Cheng-Chu Zeng, Iron-catalyzed Minisci acylation of N-heteroarenes with $\alpha$-keto acids, Tetrahedron, Volume 75, Issue 10, 8 March 2019, Pages 1425-1430.

10. X. Bi, J. Li, E. Shi, H. Wang, R.Gao, J. Xiao, Ru-catalyzed direct amidation of carboxylic acids with N-substituted formamides, Tetrahedron, Vol. 72 (2016), pp. 8210-8214.

11. L. Cheng, X. Ge, L. Huang,Direct amidation of non-activated phenylacetic acid and benzylamine derivatives catalysed by $\mathrm{NiCl}_{2}$, Royal Society open science, Vol. 5 (2018), 171870.

12. S.A. Ghorpade, D.N. Sawant, N.Sekar, Triphenyl borate catalyzed synthesis of amides from carboxylic acids and amines, Tetrahedron, Vol. 74 (2018), pp. 6954-6958.

13. Singh, Dhananjoy Chingangbam, R. A. N. J. I. T. P. H. U. R. A. I. L. A. T. P. A. M. Sharma, and J. M. Laishram."The karyotypic studies of three local shallot of Manipur, India." International Journal of Humanities and Social Sciences 5.2 (2016): 17-22.

14. Hemantkumar M.Savanur, Shruti S. Malunavar, PavankumarPrabhala, Suraj M. Sutar, Rajesh G.Kalkhambkar, Kenneth K.Laali, Synthesis of diverse libraries of carboxamides via chemoselective $N$-acylation of amines by carboxylic acids employing Brønsted acidic IL [BMIM(SO3H)][OTf], Tetrahedron Letters, Volume 60, Issue 42, 17 October 2019, 151159.

15. JyotiOmprakashRathi, Ganapati SubrayShankarling, Concentrated solar radiation aided energy efficient and chemoselective protocol for $N$-acylation and $N$-formylation reactions in aqueous medium, Solar Energy, Volume 189, 1 September 2019, Pages 471-479. 
16. Jiahui Chen, Jing Jia, ZiyiGuo, Jitan Zhang, MeihuaXie, NH4I-promoted N-acylation of amines via the transamidation of DMF and DMA under metal-free conditions, Tetrahedron Letters, Volume 60, Issue 21, 23 May 2019, Pages 1426-1429.

17. Q.H. Zhanga, B.S. Houa, Y.Y. Lia, G.Y. Zhua, H.F. Liua,b and G.A. Zhang, Two novel chitosan derivatives as high efficient ecofriendly inhibitors for the corrosion of mild steel in acidic solution, Corrosion Science. 2020, 164, 108346-10842.

18. Dhawan, G. E. E. T. A. N. J. L. I. "Female heterogamety revealed by application of differential staining technique in a species of Lepidoptera." International Journal of Applied and Natural Sciences 5.4 (2016): 127-132.

19. B.S. Houa, Q.H. Zhanga, Y.Y. Lia, G.Y. Zhua, H.F. Liua,b and G.A. Zhang, A pyrimidine derivative as a high efficiency inhibitor for the corrosion of carbon steel in oilfield produced water under supercritical CO2 conditions, Corrosion Science. 2020, 164, 108334-108340.1

20. [16] Chen-Xiang Wang, Xue-Fen Zhang, A non-particle and fluorine-free superhydrophobic surface based on one-step electrodeposition of dodecyltrimethoxysilane on mild steel for corrosion protection, Corrosion Science. 2020, 163, 108284108289.

21. Elyor Berdimurodov, Abduvali Kholikov, Khamdam Akbarov, Innat Nakhatov, Nigora Kh Jurakulova, Nurbek Umirov, Adsorption Isotherm and SEM Investigating of Cucurbit [n] Urils Based Corrosion Inhibitors with Gossypol for Mild Steel in Alkaline Media Containing Chloride Ions, Advanced Engineering Forum. 2017, 23, 13-20.

22. Wilfred Emoria, Run-Hua Zhanga, Peter C. Okaforc, Xing-Wen Zhenge, Tao Hef, Kun Weif, Xiu-Zhou Lina, Chun-Ru Cheng, Adsorption and corrosion inhibition performance of multi-phytoconstituents from Dioscorea septemloba on carbon steel in acidic media: Characterization, experimental and theoretical studies, Colloids and Surfaces A. 2020, 590, 124534-124541.

23. Elyor Berdimurodov, Abduvali Kholikov, Khamdam Akbarov, D Nuriddinova, Polarization Resistance Parameters of AntiCorrosion Inhibitor of Cucurbit [N] Urils and Thioglycolurils in Aggressive Mediums, Advanced Engineering Forum. 2018, 26, 74-86.

24. M. Eldesoky, Hala. M. Hassan, Abdu Subaihi, Abeer El Shahawy, and Thoraya A. Farghaly, Water Pipes Corrosion Inhibitors for Q235 Steel in Hydrochloric Acid Medium Using Spiropyrazoles Derivatives, Coatings. 2020, 10, 167-172.

25. Rauf and E. Mahdi, Evaluating Corrosion Inhibitors with the Help of Electrochemical Measurements Including Electrochemical Frequency Modulation, Int. J. Electrochem. Sci. 2012, 7, 4673 - 4685.

26. E. Berdimurodov, K. Akbarov, A. Kholikov, Electrochemical Frequency Modulation and Reactivation Investigation of Thioglycolurils in Strong Acid Medium, Advanced Materials Research. 2019, 1154, 122-128.

27. Abdelaziz S. Fouda, Mohamed A. Ismail, Aliaa M. Temraza and Ashraf S. Abousalem, Comprehensive investigations on the action of cationic terthiophene and bithiophene as corrosion inhibitors: experimental and theoretical studies, New J. Chem. 2019, 43, 768-789.

28. Elyor Berdimurodov, J Wang, Abduvali Kholikov, Khamdam Akbarov, Bakhtiyor Burikhonov, Nurbik Umirov, Investigation of a New Corrosion Inhibitor Cucurbiturils for Mild Steel in 10\% Acidic Medium, Advanced Engineering Forum. 2016, 18,21 -38.

29. Jamshid Chuliyev, Feruzabonu Yusupova, Abduakhad Kodirov, Kambarali Turgunov, Elyor Berdimurodov, Synthesis, X-Ray Characterization, IR Vibrational Frequencies, NMR Chemical Shifts and DFT Properties of 2,7-Dimethyl-2,7-Dicyanide-3,6Diazaoctane, International Journal of Innovative Technology and Exploring Engineering. 2020, 9, 396-404. 